\title{
Young Cancer Patients as Future Leaders in the Global Knowledge Economy
}

\author{
Christabel K Cheung, PhD, MSW \\ University of Hawaii, USA
}

Submission:May 06, 2018; Published: May 11, 2018

"Correspondence Address: Christabel K Cheung, PhD, MSW, Assistant Professor, University of Hawaii, Myron B, Thompson School of Social Work, 2430 Campus Road, Gartley Hall, Honolulu, HI 96822, USA, Email: cheungck@hawaii.edu

\begin{abstract}
In December 2017, the second Global Adolescent and Young Adult (AYA) Cancer Congress (www.ayaglobalcancercongress.com) convened in Atlanta, GA, showcasing a sizeable and ever-growing body of scientific literature illuminating the unique medical and psychosocial issues of cancer diagnosed during the adolescent and young adult (AYA) period between 15 to 39 years old. Among the host of innovations in AYA oncology, I presented an argument to promote 'embodied' AYA cancer researchers as future leaders of the Global Knowledge Economy, with qualified mentorship as key to their advancement. Embodied AYA cancer researchers are academic entrepreneurs, rarefied assets primed to make meaningful contributions in The Global University, and lead the cancer research enterprise with patient wisdom.
\end{abstract}

Keywords: Psychosocial oncology; Embodied research; Survivorship; Patient engagement; Young adult cancer; Adolescent and young adult cancer; AYA

\section{Introduction}

For years, I have been defending a growing movement of teen and young adult cancer patients who also lead the scientific research that will heal them. My motivation is simple: I am one of those cancer patients. The movement began about a decade ago when the Adolescent and Young Adult Oncology (AYAO) Progress Review Group was first assembled by the National Cancer Institute (NCI) in partnership with the Livestrong Foundation. The group found no improvements in cancer survival rates over the last 30 years for patients diagnosed between the ages of 15 and 39, and major gaps in knowledge about these agedefined, adolescent and young adult (AYA) cancer patients [1]. Specifically, no one had identified the life challenges they faced after their cancer diagnosis. The bell rung, leaders of the oncology community have since responded fervently and globally. Still, the wider oncology community's motivation to fill in research gaps was vastly different from my own.

My own need to research the very cancer that was killing me began during a radiation planning visit. I should preface by saying that I didn't show up to this appointment carrying a ton of fear. On the contrary, I was actually treating this visit as a formality before I had to complete radiation treatments that were annoyingly interrupting the main event of my bone marrow transplant. I knew the one result of this 'planning visit' would be the production of a face mask for the purpose of immobilizing my head and shoulders during treatment. It was a surprise, then, when fear crept in and took me out like a sniper.

\section{'Don't move'}

The radiation treatment room was an austere collection of rotating tables, cameras and machinery suspended above and below, and what my friend, Jo Ann Madigan, decided looked like an electric chair. Every piece of equipment had an associated giant graph or egg-timer dial-a geometry textbook come to life. I lay on the coldness of the stainless steel table and focused my thoughts on my breath, my prayer, and their instruction, "Don't move!" while they pushed and pulled me into what was supposedly straightness, but felt more like contorted cramped-ness. They took numerous x-rays, photos and sharpied coordinates to my face, chest, shoulders and head. Then, came what I can only describe as the world's heaviest stinky hot pizza dough made of lead, which they blanketed over my face and upper body. As the dough hardened and dried, it pinned me deeper into suffocating restraint.

Upon drying, they bolted the mask down to the table, squashing me even more until I was completely immobilized and unable to even swallow. You could probably count my teeth 
from outside my face. Remember that stinky rough-housing bully from childhood with sticky hands, who didn't know or care about his own strength? Imagine him pinning you down on an unforgiving metal surface by sitting on your face until you could barely breathe, and then proceeding to write with a sharpie all over your face, head, shoulders and chest.

The worst part was that halfway into the mask drying process, my gown slipped off, but no one scooted it back on, and I couldn't speak or move. Then, came a parade of random workers in and out of the room getting stuff, talking, laughing. I was dehumanized-naked and trapped in front of so many strangers. A swell of tears crashed against my humiliation.

\section{'Embodied' Researchers}

Patient engagement -- when patients are included as advisors of existing studies -- has been touted as critical to the validation of research efforts worldwide $[2,3]$. But what if teen and young adult cancer patients were not merely tapped as advisors, but served as leaders of empirical investigation? 'Embodied research' is defined as a scientific method led by stakeholders aimed at deriving empirical evidence that would not otherwise be found $[4,5]$.

Embodied AYA cancer researchers possess the rare duality of hard-earned scientific skill and exclusive access to evidence that would not otherwise surface. With the optics of a patient's lens, embodied AYA cancer researchers have the potential to contribute to creating scientific knowledge in four ways. First, embodied AYA researchers can draw upon wisdom from lived experiences to improve the design and implementation of research, as well as the dissemination of results. Studies developed by and findings presented by cancer patients hold greater credibility in clinical practice. Second, embodied AYA researchers have an authentic motivation to investigate patient-centered questions that contribute to transdisciplinary knowledge, since their experience of cancer is not bound by the limits of a particular professional perspective.

Third, embodied researchers can ensure fidelity to both evidence-based practice and practice-based evidence, as the orientation of patient perspective can elucidate potential strengths and weaknesses. Fourth and finally, the continued development of new embodied AYA cancer researchers can enhance sociocultural considerations, by responding to current and upcoming AYA age cohorts and the distinct features of their respective generational contexts.

Stakeholders have made notable contributions to AYA oncology research. For example, one breakthrough in psychosocial research is a theorization of AYA cancer patients' developmental pathways that goes against the dominant discourse of AYA oncology to date-which assumes that all AYAs must accomplish certain developmental tasks to achieve positive growth into adulthood. Dr. Chad Hammond [6] proposes a more complex theorization of AYA psychosocial development as the interplay of four interrelated sociodemographic contexts succinctly described as: Precarious labor conditions that affect AYAs' financial and work lives; Changing timetables and priorities for achieving developmental tasks; Sexual and gender plurality; and Expanding cultural diversity of AYAs [6].

A stakeholder himself, Dr. Hammond's interest in AYA cancer patients grew from his first-hand experience as a 15-year-old, caring for his uncle who passed from leukemia in his 40s. His lived experience as a caregiver likely influenced his incisive characterization of AYA cancer patients' psychosocial development. It would be reasonable to presume that there are many other cancer researchers whose careers are similarly inspired.

In fact, rare as they are, AYA cancer-patient-turnedresearchers are "academic entrepreneurs" (A. Roy, personal communication, June 1, 2017), who are already making a difference in The Global University. An accomplished oncologist at Washington University, Lukas Wartman, MD is a three-time survivor of acute lymphoblastic leukemia, diagnosed at the ages of 25 years, 30 years, and 33 years old. In parallel with his continued contributions to the field of oncology as a clinician, Dr. Wartman has raised awareness about the debilitating consequences of graft versus host disease (GVHD), which has become a chronic problem resulting from aggressive cancer treatments.

Teryn Mattox, MPA, was diagnosed with Stage 4 colon cancer at the age of 34, only a few months after the birth of her daughter. Today, Ms. Mattox serves as a senior policy analyst at the RAND Corporation, and is an award recipient of the esteemed PatientCentered Outcomes Research Institute (PICORI) for her AYA cancer advocacy. Adriana Nicholson Vest, PhD, is an aspiring medical student at Emory University and AYA advisor to the University of Southern California, who was diagnosed with Hodgkin's lymphoma as a 26-year-old PhD candidate. Similarly, Eric Galvez, DPT, is pursuing his second doctorate degree at the University of Texas Health Science Centre, after being diagnosed with brain cancer at the age of 32. Dr. Galvez also founded Mass Kickers Foundation, a nonprofit organization that promotes AYA cancer survivors.

As an embodied AYA cancer researcher myself, I was diagnosed with Hodgkin's lymphoma at the ages of 32 and 34, while working as a nonprofit executive director and community activist in San Francisco, CA. After emerging from aggressive cancer treatments, I committed to earning a $\mathrm{PhD}$ in order to contribute to the empirical knowledge base on AYA cancer. Fortuitously, I was gifted with embodied AYA cancer mentorship from Brad Zebrack, PhD, MSW, MPH, FAPOS, professor of social work at the University of Michigan. Dr. Zebrack was diagnosed with Hodgkin's lymphoma at 25-years-old, and subsequently became an oncology social worker and earned his PhD. Today, he is an internationally recognized scholar in AYA psychosocial oncology, and is esteemed for his scientific contributions and patient advocacy. 


\section{Cancer Therapy \& Oncology International Journal}

\section{Qualified Mentorship}

Cancer patients continue to be cancer patients on the job, with material needs. They have legitimately expanded needs for practical information and support related to finances, health insurance, physical disability, cognitive challenges, and reintegration into the general healthy (non-cancer) population. Mentors can help alleviate these challenges within the academic environment, and advise emerging scholars on moving between patient advocacy and scientific contribution. Dr. Zebrack's early advice to me was to always prioritize scientific rigor saying, "Your science must stand on its own legs." Additionally, my doctoral training was bolstered by day-to-day advisement from my compassionate-but-tough faculty advisor at UCLA, Robert F. Schilling, PhD, MSW. Dr. Schilling was not afraid to confront me with some of the stark realities of navigating longstanding institutions of knowledge creation, which proved to be advantageous in carving an ascendant career trajectory.

\section{Claiming Wisdom}

Embodied researchers bring the wisdom of lived experience to their scientific efforts. If embodied AYA cancer researchers do not claim their wisdom, then this knowledge would not exist. Lived experience cannot be accessed in any other way. Who but I would recall how the technician who made my radiation mask kept muttering to himself that I still needed the coordinates tattooed onto my body? Who but I would know that he only acknowledged me directly when he held up the mask like a trophy and said, "It's yours to keep after you're all done." Who but I would know that my discomfort made me recall a three-year-old girl with a brain tumour, who was in the recovery room with me after my last surgery. She cried with such raw desperation and kept repeating, "Let me go! Let me go! Let me go!" In thinking and praying for this baby girl since our encounter, I feel blessed that I have the ability to intellectualize my experience that her young mind does not. I know that I'm not being punished. I know this is all temporary-I will either get better or die. But I want her to only get better. Remembering her plea also made me think that although I sometimes convey my emotions with complexity, at the heart of it all, I simply want to be let go too.

I think that when cancer people look at each other, there is a kind of compassion of knowing, not pity, that makes us want to save our comrade more than ourselves. My friend Jo Ann shared that while I was getting fitted, she met an older woman in the waiting room whose husband had three different cancers. His wife was watching us and remarked about me to Jo Ann, "She's so young." Young is relative and so is suffering. We don't suffer in life because we deserve to. And somehow, we are able to find just enough love and incomprehensible courage to face our fears if we keep on living.

\section{Conclusion}

Embodied AYA cancer researchers are academic entrepreneurs, rarefied assets primed to lead the global knowledge economy. They are as critical to leading the cancer research enterprise as embodied researchers in any other discipline, and mentorship is key to their advancement. Given today's sociopolitical context of less stable financial backing for AYA oncology research and attacks on the conduct of science, it is timely and necessary to promote scientific methods that expedite the process of deriving evidence with fidelity to credible techniques. Furthermore, if AYA psychosocial oncology research is to keep pace with the speed of technological advances in basic science, then embodied AYA researchers are not a nice-to-have, but a must. The voices of these early investigators do not need to be raised; they are inherently self-actualized, motivated, and primed. Rather, The Global University should enable necessary mentorship and resources, and make room for future embodied AYA cancer researchers to claim their wisdom.

\section{Acknowledgment}

The author thanks Teen Cancer America-in particular, Simon Davies, Hon DEd and Stuart Siegel, MD- for funding support of her presentation, "Patients as future leaders of her global knowledge economy," at the second Global AYA Cancer Congress in Atlanta, GA. The author also thanks Bradley J Zebrack, PhD, MSW, MPH, FAPOS; Charles R. Lawrence, III, JD; Michael B. Kantar, PhD; and Susan Scutti for their editorial review. Furthermore, the author is grateful for advisement from the following academic mentors: Robert F. Schilling, PhD, MSW; Bradley J Zebrack, PhD, MSW, MPH, FAPOS; Ananya Roy, PhD, MA; Patricia A. Ganz, MD; Todd M Franke, PhD, MSW; David Cohen, PhD, MSW; Ninez Ponce, PhD, MPP; Governor Michael S. Dukakis, JD; Jennie Chin Hansen, MSN, RN, FAAN; Jo Ann Madigan, MA; Marjorie Kagawa-Singer, PhD, MN, MA, RN; Patricia W. Nishimoto, DNS, FAAN, FT, MPH; and Jeffrey Berenberg, MD, MACP.

\section{Conflict of Interest}

No competing financial interests exist.

\section{References}

1. Albritton, K., Caligiuri, M., Anderson, B., Nichols, C., Ulman, D., \& Adams, H. (2006) Closing the gap: research and care imperatives for adolescents and young adults with cancer. Bethesda, MD: Department of Health and Human Services, National Institute of Health, National Cancer Institute, and the LiveStrong Young Adult Alliance.

2. Serena Barello, Guendalina Graffigna, Elena Vegni (2012) Patient engagement as an emerging challenge for healthcare services: mapping the literature. Nursing research and practice 905934: 7.

3. Olsen LA, Saunders RS, McGinnis JM (2011) Patients charting the course: citizen engagement in the learning health system: workshop summary. National Academies Press, Washington (DC), USA.

4. Rachelle Chadwick (2017) Embodied methodologies: challenges, reflections and strategies. Qualitative Research 17(1): 54-74.

5. Spatz B (2017) Embodied Research: A Methodology. Liminalities 13(2).

6. Hammond Chad (2017) Against a singular message of distinctness: challenging dominant representations of adolescents and young adults in oncology. Journal of adolescent and young adult oncology 6(1): 4549. 
Your next submission with Juniper Publishers will reach you the below assets

- Quality Editorial service

- Swift Peer Review

- Reprints availability

- E-prints Service

- Manuscript Podcast for convenient understanding

- Global attainment for your research

- Manuscript accessibility in different formats

( Pdf, E-pub, Full Text, Audio)

- Unceasing customer service

Track the below URL for one-step submission https://juniperpublishers.com/online-submission.php 